\title{
Design of Tire Wear Check System of Car with Laser Sensors
}

\author{
S.H. Baek,J.W. Jang \\ Department of computer engineering \\ Dong-Eui University \\ Busan 614-714, Korea
}

\begin{abstract}
If tire a little abnormal condition, tire is important one of components in which driver and passenger was effected safety. But there can be a variety the tire problem, there will generally be divided normal wear and abnormal wear. Wear cause of tire is various causes, such as lack of tire pressure, tire side wear, rapid tire wear. The causes has a lot of the case where the multiplicative various causes(such as quality of the tire, driving conditions, air pressure, rotation instruction state, the attachment state of the wheel etc). The general wear is the wear among the car driving, so, you can replace the change of the tire according to the appropriate distance. But, abnormal wear is worn of some part of tire unlike the general wear. Until now, the method to check abnormal tire wear is that a mechanic checks tires with naked eyes and hands to confirm uneven tire wear. However, drivers are embarrassed when facing varied and vague rules of uneven wear, even for each tire.In this paper, it designs a system to check each tire wear by using multiple laser sensors in order to make up for this weakness and overcome the limits of subjective judgment and obtain objective, accurate judgment.
\end{abstract}

Keywords-vehicle tire; abnormal tire wear; laser sensor; android; normal tire wear; tire; vehicle

\section{INTRODUCTION}

Vehicle tire utilizes the rubber elasticity and air contractibility to support car weight, deliver driving force and braking power of a car to the road surface as well as relieve the impact from road surface in order to switch or maintain travelling direction of a car. Tire plays a very important role in driving [1].

The life span of this important tire depends on the degree of vehicle tire wear. Wear life of vehicle tire is directly related to vehicle maintenance cost. Drivers usually have great complaints when tires are replaced often. Also, when tire wear is advanced, there will be a crack or damage on the tire. If the car in this state continues to drive, it has longer braking distance and slips more often, which increases the risk of accidents. Seriously worn-out tires cause "hydroplaning", and when it happens, the car slips easily. Depending on the wear degree of tire, the probability of car accidents increases and it leads to serious accidents, so checking tire wear is essential [2 3].

Because the wear of tire is designed flat and round, generally, the wear condition of ground part has to be uniformly worn away. But, in fact, tire is happened abnormal wear phenomenon. This abnormal wear phenomenon is cause of tire wear commission, such as abnormal vibration cause of car and cause of car accident. The cause of abnormal condition wear is the driving state badness and car poor maintenance, the scarcity of tire pressure, the tire position exchange, etc.

Tire wear is a very important element for driving and car accidents. In order to generally know degree of wear tire or abnormal condition wear, the driver or mechanic check wear of tire and abnormal condition by the naked eye. But, because explained above decide subjective judgment of checking person with tire, this method is different every each person, as a result, the driver cannot help being embarrassed by standard.

In this paper, it aims to overcome these shortcomings. A system is designed to check wear degree and any abnormal condition of each tire by using multiple laser sensors so that drivers satisfies their right to be informed from objective and correct measurement of the sensors and machine.

\section{RELATED RESEARCH}

\section{A. The Wear of Tire}

The wear of tire has relationship with tire management method or use condition or etc. When tire contacts to the load, tire get to contact the specific slope. According to this slope, tire happen unbalance on ground pressure distribution. As a result, tire happen uneven wear phenomenon, severe state of uneven wear phenomenon is called especially abnormal wear. If tire has abnormal wear, tire is shortened tire life or changed tire geometry.

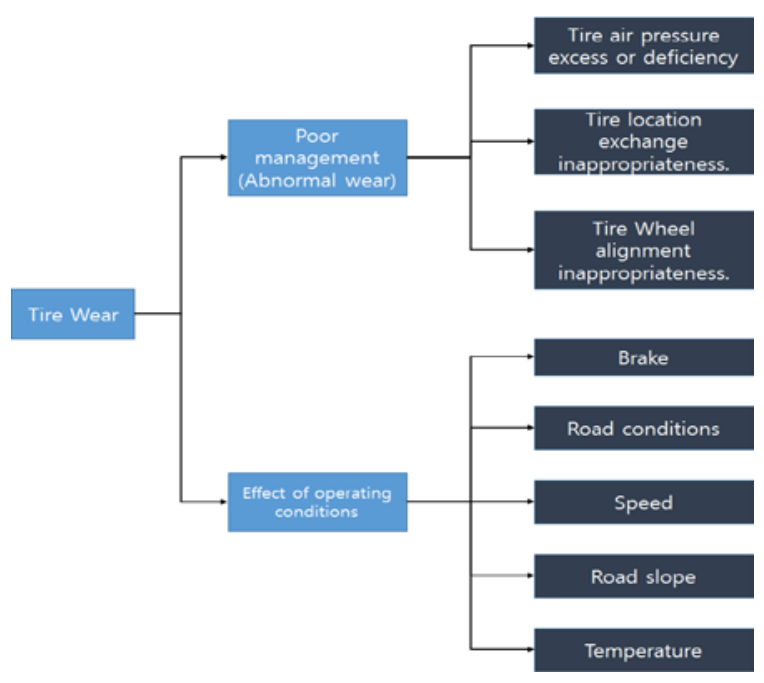

FIGURE I. KIND OF TIRE WEAR. 


\section{B. Abnormal Wear of the Tire}

If the tire pressure is higher or lower, the grounding shape of the tire get to be inappropriateness[figure 2]. Moreover, because the tire receive the good and bad effect according to the location in which it equip a tire with the wheel alignment on a car, if driver don't exchange a tire location during the long time, tire will have uneven wear phenomenon.

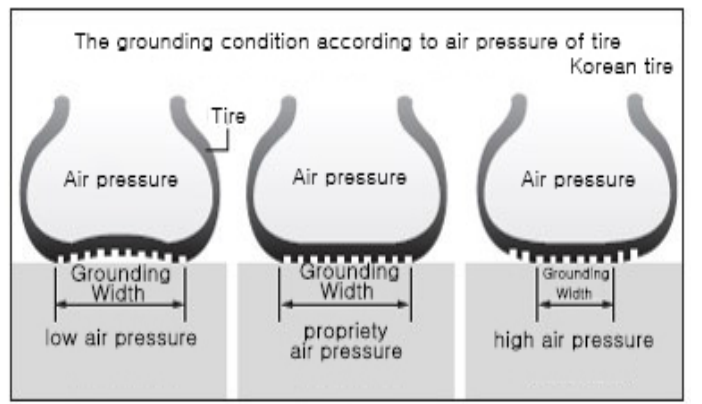

FIGURE II. THE TIRE GROUNDING ABOUT TIRE PRESSURE.

\section{SYSTEM DESIGN}

The laser sensor check system for car tire uneven wear in the paper is largely divided into two parts. One is the scanner to measure the tire wear, and the other is the integrated control server to measure the values, show to driver, and save the data[Figure 3].

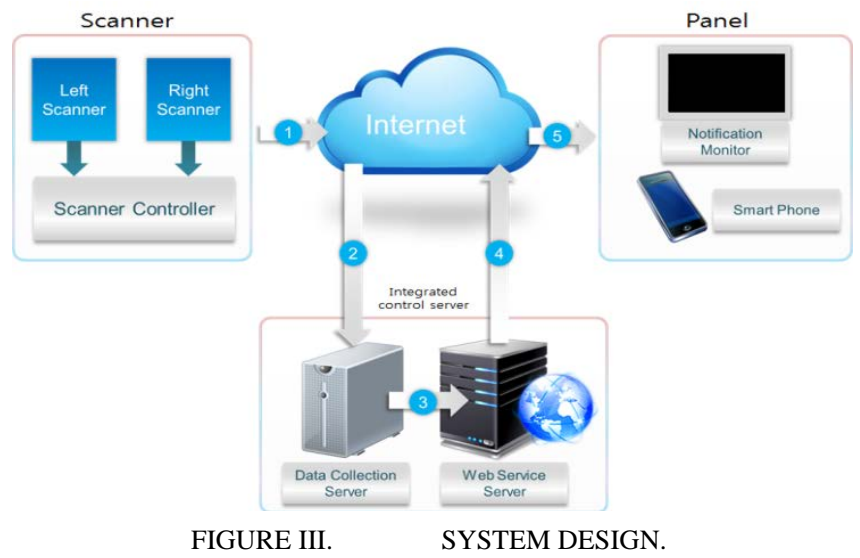

\section{A. The Scanner Design}

The scanner collects the tire information from several laser sensor attached on the road. When a car passes upside of the sensor region, these laser sensors check the tire surface and send the data to the main MCU using I/O channel. The laser sensor and the main MCU is physically connected to operate. The configuration of the scanner consists of three parts; the laser sensors, the part to handle the data from the sensors, and the part to send the data to the integrated control server.Because tire of car have basically for tires. And because each tire is different tire hole every tire maker, we will check domain of at least 4 places. We equip 4 8 laser sense in each area and will check the load condition of tire[Figure 4,5].

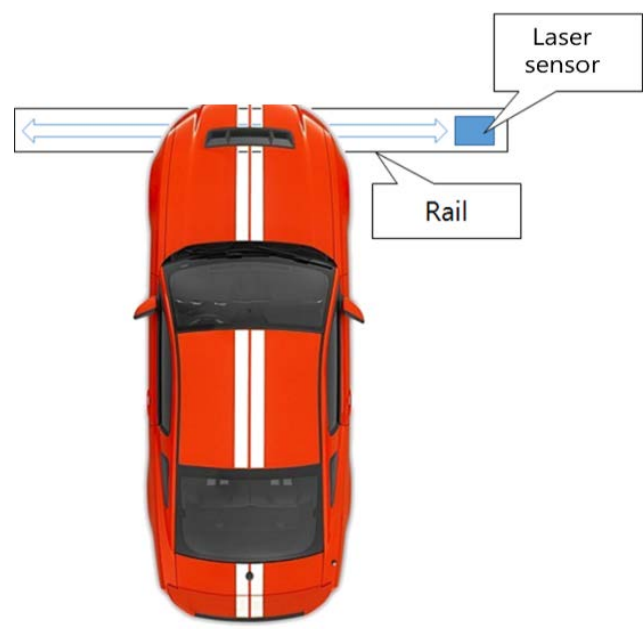

FIGURE IV.

LASER SENSOR PART OF VEHICLE [EXAMPLE 1].

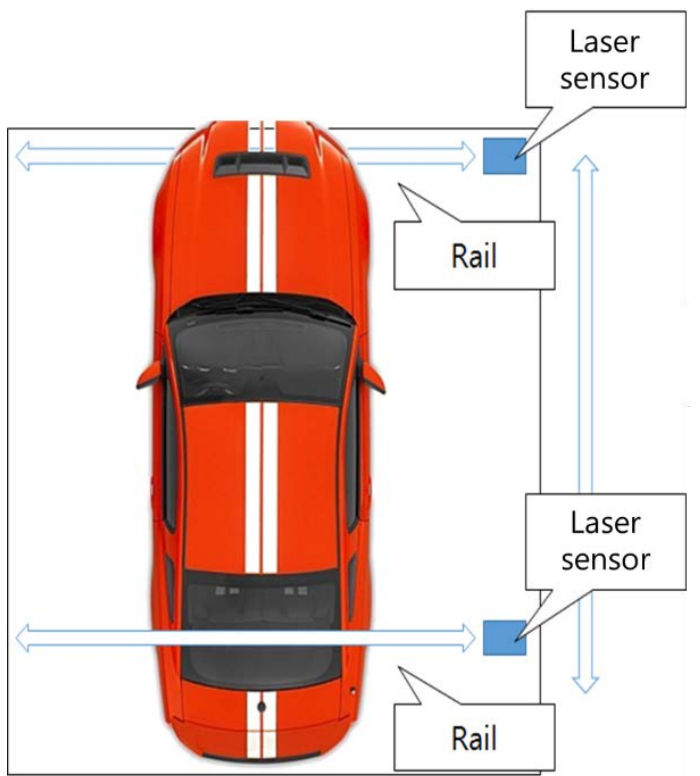

FIGURE V. LASER SENSOR PART OF VEHICLE [EXAMPLE 2].

\section{B. Panel Design}

The panel parts consist of two parts:

The first, LCS should be huge so drivers can see the tire information in real time when they enter a gas station or a pier. The large LCD shows sings like normal, warning, and danger to help drivers easily know their tire status. In addition, the warning screen informs drivers how many kilometres are left before they need to change the tire so that they can be informed the time to change the tire[Figure 6,7]. 

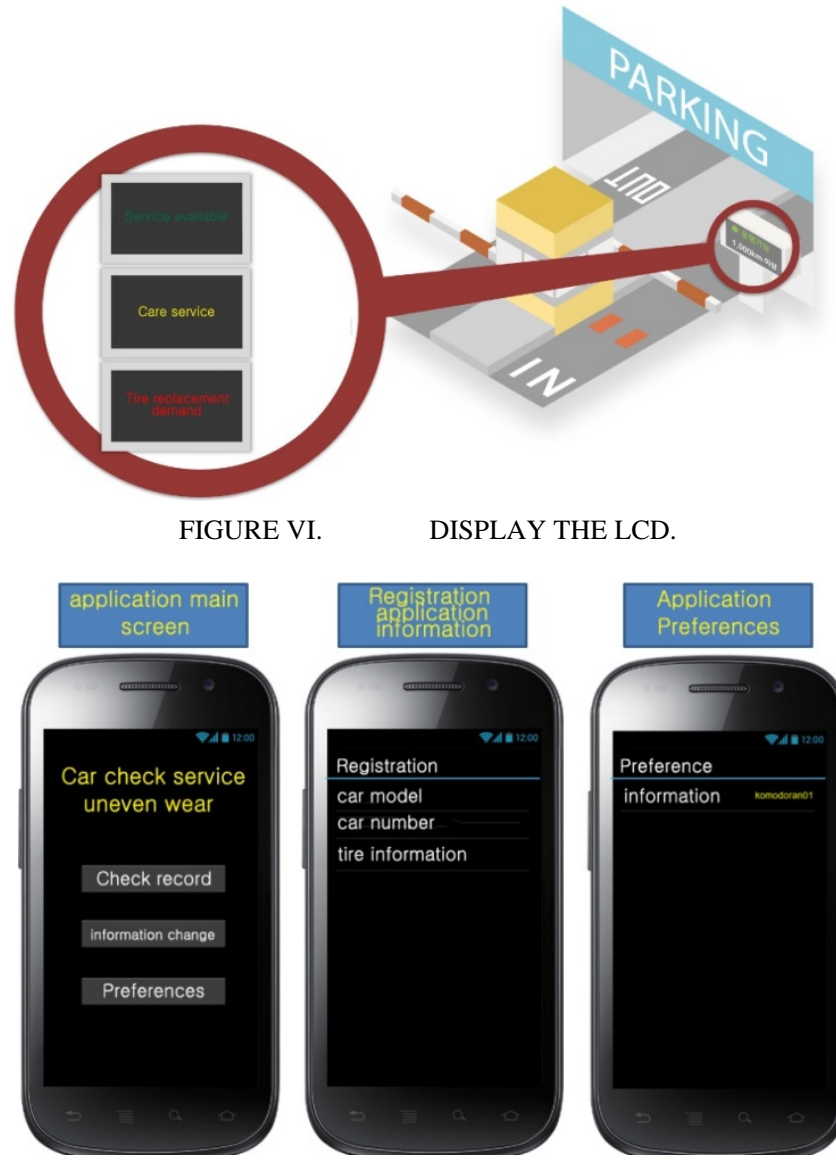

FIGURE VII.
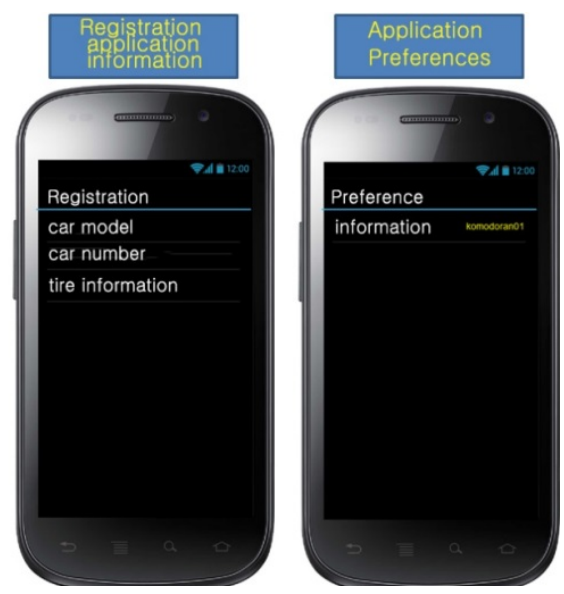

DISPLAY DETAIL THE DETAIL SMARTPHONE
SCREEN.

\section{Integrated Control Server Design}

The integrated control server saves the tire information received from uneven wear scanner and provides them to the users through their smart phone application.

The integrated control server has two servers to provide its service; uneven wear check server and web service server [Figure 8].

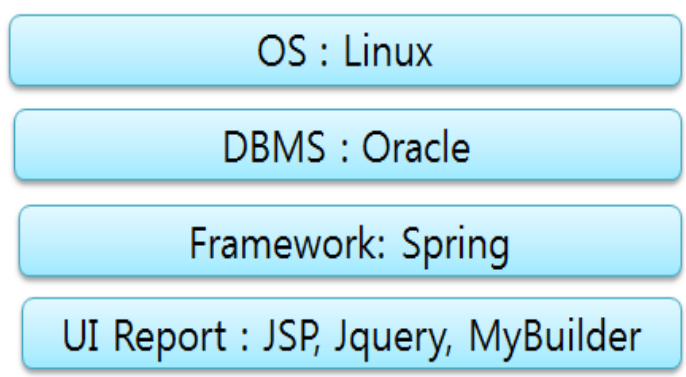

FIGURE VIII.

INTEGRATED CONTROL SERVER DESIGN.

\section{CONCLUSION}

In this paper, it designed uneven wear check system for car tires using laser sensors in order to check the wear and abnormal wear of tires.
Unlike the existing methods, this system uses laser sensors to determine current abnormal wear state objectively and also check the degree of tire wear simultaneously. Thus, the users can be provided with more accurate service than before. Furthermore, the drivers can check their tire wear whenever wherever because of the smart phone application which provides the tire data. However, to implement a system like this, it has a problem to receive and handle all the data related with all the tires of vehicles. Also, the wear degree should be confirmed by the depth of the tire tread groove, but we don't have a measure to gauge the tread depth with the laser sensors.

The future subject will be the application and establishment of the system. It will apply and realize the system designed in this paper to build a perfect system through real tests and debugging. Further, it will establish a more perfect system by researching the data related to every tire of vehicles. By connecting to OBD-II, the automotive network, and real-time alarm for tire replacement time, we can build the system to secure maximum safety for tire wear.

\section{ACKNOWLEDGMENT}

This work was supported by the Brain Busan 21 Project in 2014.And this work was supported by the Nurimaru R\&BD Project(Busan IT Industry Promotion Agency) in 2014.

\section{REFERENCES}

[1] Chung, Soo Sik, Jung, Won Wook, Lee Sang JuKoh Bum Jin, Choi Young Sam, Evaluation and Analysis of Wheel alignment Effecting on Tire Uneven Wear, The Korean Society of Mechanical Engineers 2007 spring conference, pp318-322, 2007. 5

[2] Park Sung - Jin, "Car tire care, do your car is safe ?”, "http://blog.skenergy.com/738”

[3] Song youn-gi, "abnormal wear of the tire and the cause, 1991, pp46-48 [8] H. Nowakowska, M. Jasinski, P. S. Debicki and J. Mizeraczyk, "Numerical analysis and optimization of power coupling efficiency in waveguide-based microwave plasma source," IEEE Transactions on Plasma Science [Online], vol. 39, no. 10, pp. 1935-1942, 2011, Available:

xpl/articleDetails.jsp?arnumber $=6003795$

\section{http://ieeexplore.ieee.org/}

